\title{
Clinical and radiologic features of the first cured Coronavirus disease 2019 (COVID-19) patient in Guangzhou City, China
}

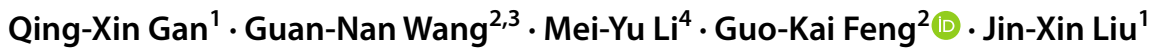

Received: 13 March 2020 / Revised: 21 July 2020 / Accepted: 14 August 2020 / Published online: 25 August 2020

(c) Springer Nature Singapore Pte Ltd. 2020

\begin{abstract}
To determine changes in clinical and radiologic findings associated with Coronavirus disease 2019 (COVID-19) from diagnosis to recovery, we retrospectively reviewed the diagnosis and treatment records of the first patient cured of COVID-19 in Guangzhou. A 55-year-old woman from Wuhan was admitted to the hospital isolation ward with the chief complaint of "cough for 11 days and once fever 8 days ago" on January 22, 2020. COVID-19 was laboratory confirmed by reverse transcription polymerase chain reaction (RT-PCR) assay, and she received conventional antiviral therapy, such as moxifloxacin, traditional Chinese medicine, and arbidol. Repeat chest-computed tomography (CT) scans were performed on days 13 and 19 of her illness. The former showed radiologic findings, including ground-glass opacities (GGOs), which revealed viral pneumonia; the latter revealed that the previous lesions had been significantly absorbed. The lesions on CT scans were consistent with the changes in the course of disease. Some drugs, such as traditional Chinese medicine and arbidol, might play an important role in the recovery of COVID-19 patients. This study provides some new insights into the formulation of a timely and effective diagnostic and therapeutic strategy to cure patients with COVID-19.
\end{abstract}

Keywords Coronavirus disease $2019 \cdot$ Severe acute respiratory syndrome coronavirus $2 \cdot$ Radiologic features $\cdot$ First cured patient

Dear Editor,

Coronavirus disease 2019 (COVID-19), caused by severe acute respiratory syndrome coronavirus 2 (SARS-CoV-2), has spread worldwide [1], with 5,934,936 confirmed cases

Qing-Xin Gan, Guan-Nan Wang, and Mei-Yu Li contributed equally to this work.

Electronic supplementary material The online version of this article (https://doi.org/10.1007/s42058-020-00045-z) contains supplementary material, which is available to authorized users.

Guo-Kai Feng

fengguok@sysucc.org.cn

$\triangle$ Jin-Xin Liu

Liujx83710378@126.com

1 Department of Radiology, Guangzhou Eighth People's Hospital, Guangzhou Medical University, No. 8, Huaying Road, Baiyun District, Guangzhou 510060, People's Republic of China

2 State Key Laboratory of Oncology in South China, Collaborative Innovation Center for Cancer Medicine, Sun as of May 31, 2020 [2]. We would describe the clinical and radiologic features of the first cured case of COVID-19 in Guangzhou, a city with hundreds of confirmed cases.

On January 22, 2020, a 55-year-old woman from Wuhan was admitted to the hospital with the chief complaint of "cough for 11 days and once fever 8 days ago" on her visit in Guangzhou (Fig. 1). She reported a visit history to an elderly man with fever of unknown origin in Wuhan on January 11. After that, she had initial symptoms of dry cough, sore throat, and fatigue on January 12 (day 1 of the illness). On day 3 of the illness, she had a fever of $38^{\circ} \mathrm{C}$ and went to

Yat-Sen University Cancer Center, Guangzhou 510060, People's Republic of China

3 Department of Head and Neck, Sun Yat-Sen University Cancer Center, Guangzhou 510060, People's Republic of China

4 Department of Cardiovascular Internal Medicine, Guangzhou Eighth People's Hospital, Guangzhou Medical University, No. 8, Huaying Road, Baiyun District, Guangzhou 510060, People's Republic of China 


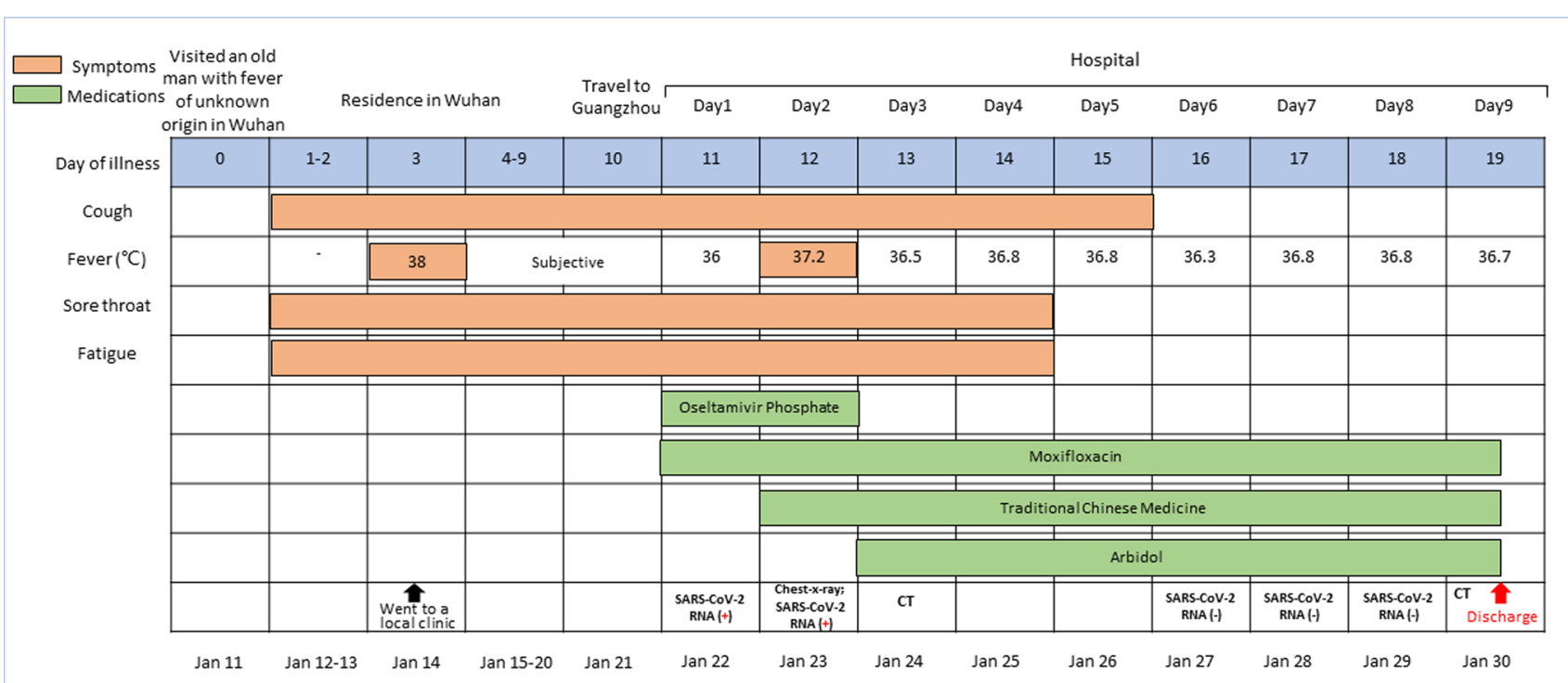

Fig. 1 Timeline of the disease course according to days from initial presentation of illness and days from hospital admission, January 12-30, 2020. SARS-CoV-2 severe acute respiratory syndrome coronavirus $2, C T$ computed tomography

a local clinic in Wuhan. She was diagnosed with "pulmonary infection" but gave no exact details. After some treatments (medication was unknown), she became slightly better (Fig. 1).

She was immediately admitted to the isolation ward and received the conventional anti-infection therapy of oseltamivir phosphate (75 mg twice daily, orally) and moxifloxacin (0.4 g once daily, orally). Nasopharyngeal and oropharyngeal swabs were collected. COVID-19 was laboratory confirmed by reverse transcription polymerase chain reaction (RT-PCR) assay. On January 23 (day 12 of the illness), a repeated RT-PCR was performed for the confirmation of COVID-19 (Fig. 1).

On day 12 of the illness, the patient had a cough, a sore throat, fatigue, and a slight fever (Fig. 1). Chest X-ray showed evidence of pneumonia in the lower and upper lobes of the right lung and the lower lobe of the left lung (Figure $\mathrm{S} 1$ ). Blood biochemical test results suggested normal levels of biochemistry parameters. Oxygen partial pressure $\left(\mathrm{PO}_{2} 71 \mathrm{mmHg}\right)$ and blood oxygen saturation $\left(\mathrm{SO}_{2} 91 \%\right)$ were moderately reduced. Due to mild hypoxia, there was an increased level of lactic acid in the patient (Table S1). To relieve her symptoms, she received several traditional Chinese medicines.

On day 13 of her illness, noncontrast-enhanced chestcomputed tomography (CT) revealed approximately 24 peripheral patchy ground-glass opacities (GGOs) (Fig. 2a, yellow arrow), 1 consolidation (Fig. 2a, orange arrow), 16 interlobular septal thickenings (Fig. 2c) and subpleural curved lines (Fig. 2e) in her lungs (Table 1), suggesting lung inflammation caused by viral infection. When a multifocal lesion had an unclear margin, the absence of a normal lung tissue interval revealed only one lesion, and the presence of normal lung tissue surrounding the lesion revealed several separate lesions. Each lung was divided into three zones: upper (above the carina), middle (below the carina up to the inferior pulmonary vein), and lower (below the inferior pulmonary vein) zones [3]. Each lung zone was assigned a semiquantitative score based on the following: score $0,0 \%$ involvement; score 1 , less than $25 \%$ involvement; score 2 , $25 \%$ to less than $50 \%$ involvement; score $3,50 \%$ to less than $75 \%$ involvement; and score $4,75 \%$ or greater involvement. The scores of this set of CT scans were 1 for the left upper zone, 2 for the right upper zone, 2 for the left middle zone, 2 for the right middle zone, 3 for the left lower zone, and 2 for the right lower zone. Therefore, the total CT score was 12 (Table 2). CT scans were obtained using a General Electric (GE) Optima CT680 64-row 128-slice spiral CT scanner with the following parameters: 1.0-milimeter section thickness, $120 \mathrm{kV}$ and $210 \mathrm{~mA}$.

Accordingly, antiviral treatments with a hemagglutinin inhibitor (arbidol, $0.2 \mathrm{~g}$ three times daily, orally) were given instead of oseltamivir phosphate (Fig. 1).

The conditions of the patient improved significantly on days 14 through 18 of her illness. From days 16 to 18 of her illness, three consecutive RT-PCR assays showed that the SARS-CoV-2 virus was no longer detectable in the patient (Fig. 1).

On day 19, chest CT showed that the previous GGOs were no longer present (Fig. 2b, brown arrow); in addition, part of the subpleural curved lines had disappeared (Fig. 2f). Moreover, lesions with increased density caused by partial absorption with fibrotic streaks (Fig. 2b, brown arrow) and interlobular septal thickenings were more visible 
Fig. 2 CT scans of the patient. $\mathbf{a}, \mathbf{c}, \mathbf{e}$ were on day 13 of illness; $\mathbf{b}, \mathbf{d}, \mathbf{f}$ were on day 19 of illness. a GGO (yellow arrow) and consolidation (orange arrow); b fibrotic streaks showing absorption of GGO (brown arrow) and stable consolidation (white arrow); $\mathbf{c}, \mathbf{d}$ the formation of interlobular septal thickening from day 13 (blue arrow) to day 19 (purple arrow) of illness; e, f the disappearance process of subpleural curved lines from day 13 (pink arrow) to day 19 (gray arrow) of illness. GGO ground-glass opacity, $C T$ computed tomography

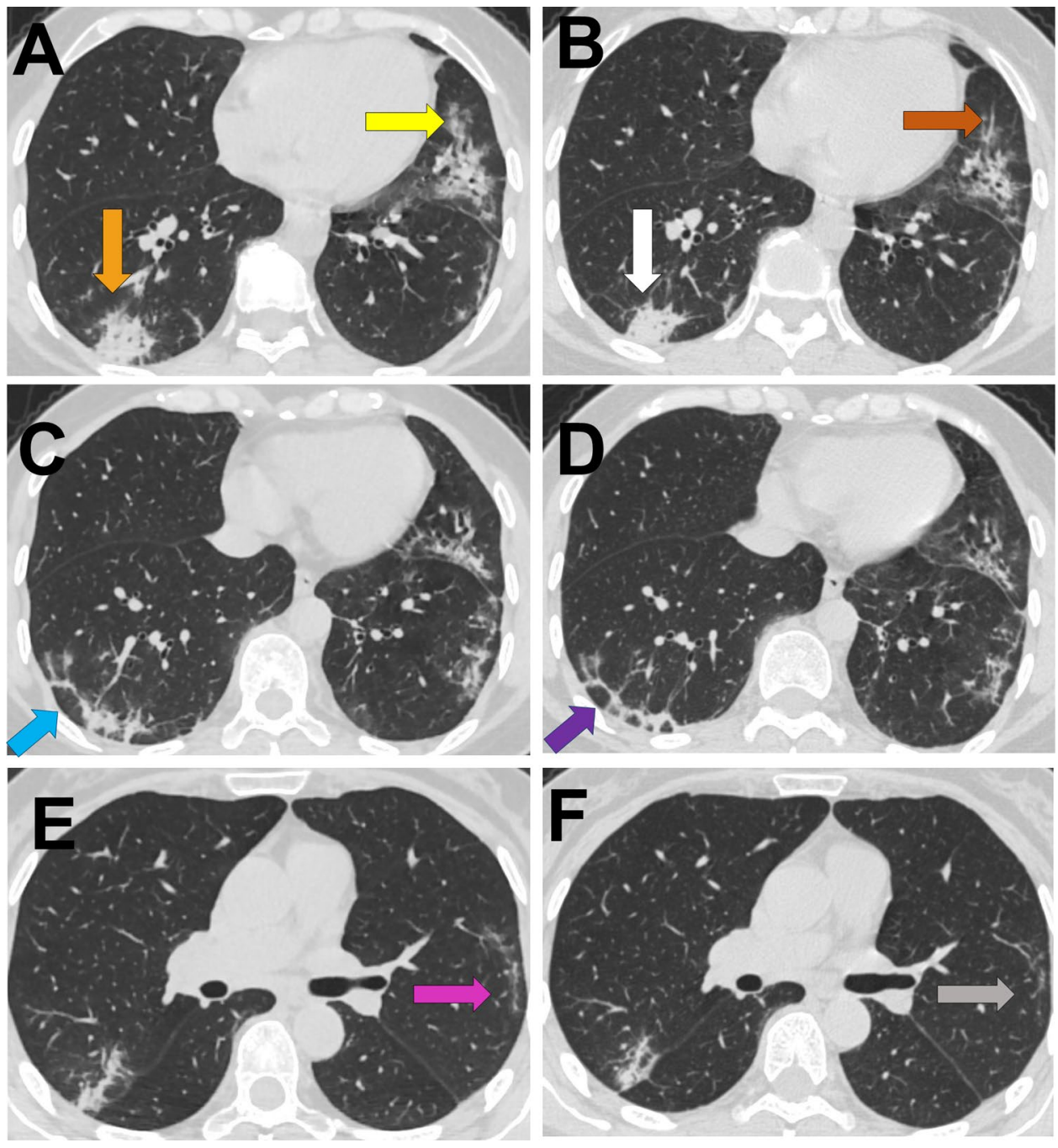

Table 1 Comparison of lesions on CT scans between day 13 and day 19 of illness

\begin{tabular}{|c|c|c|c|c|c|}
\hline & Ground-glass opacities & Consolidation & $\begin{array}{l}\text { Interlobular septal } \\
\text { thickening }\end{array}$ & Subpleural curved lines & Total \\
\hline Lesions on day 13 & 24 & 1 & 16 & 5 & 46 \\
\hline Lesions on day 19 & 0 & 1 & 18 & 3 & 22 \\
\hline Lesions (day 19-day13) & -24 & 0 & +2 & -2 & -24 \\
\hline Absorption rate & $100.00 \%$ & - & - & $40.00 \%$ & $52.18 \%$ \\
\hline Progressive rate & - & - & $12.50 \%$ & - & - \\
\hline $\mathrm{CT}$ results & Complete resolution & - & Increased & Partial resolution & - \\
\hline
\end{tabular}

$C T$ computed tomography

Table 2 Comparison of semiquantitative scores for CT scans between day 13 and day 19 of illness

\begin{tabular}{llllllll}
\hline & $\begin{array}{l}\text { Left upper } \\
\text { zone }\end{array}$ & $\begin{array}{l}\text { Right upper } \\
\text { zone }\end{array}$ & $\begin{array}{l}\text { Left middle } \\
\text { zone }\end{array}$ & $\begin{array}{l}\text { Right mid- } \\
\text { dle zone }\end{array}$ & $\begin{array}{l}\text { Left lower } \\
\text { zone }\end{array}$ & $\begin{array}{l}\text { Right lower } \\
\text { zone }\end{array}$ & Total \\
\hline CT on day 13 & 1 & 2 & 2 & 2 & 3 & 2 & 12 \\
CT on day 19 & 1 & 1 & 1 & 1 & 3 & 1 & 8 \\
\hline
\end{tabular}

$C T$ computed tomography 
(Fig. 2d). However, the consolidation was stable (Fig. 2b, white arrow). The scores of this set of CT scans were 1 for the left upper zone, 1 for the right upper zone, 1 for the left middle zone, 1 for the right middle zone, 3 for the left lower zone, and 1 for the right lower zone, with a total CT score of 8 (Table 2). In general, the lung lesions were significantly absorbed compared to the previous imaging (Fig. 2; Tables 1,2).

According to the 4th edition of Guidelines for the Diagnosis and Treatment of COVID-19 Pneumonia published by the National Health Commission of the People's Republic of China, accessed on January 27, the discharge criteria were as follows: (1) afebrile for over $72 \mathrm{~h}$; (2) significant improvement in respiratory symptoms; (3) two negative consecutive RT-PCR results at least $24 \mathrm{~h}$ apart [4]. Until day 19 of her illness (January 30), the patient had been afebrile for over 6 days, and the respiratory symptoms had disappeared; three consecutive negative RT-PCR results were obtained from day 16 to 18 of illness. Therefore, the patient was discharged on the same day.

Our findings for the first cured COVID-19 patient in Guangzhou not only help in understanding the clinical and radiologic changes with the course of the illness, but also provide new insights into the diagnosis and treatment of COVID-19 pneumonia. For instance, the radiologic feature of pneumonia was added to the diagnostic criteria, and improvement on chest CT or radiograph was added to the discharge criteria in Guidelines for the Diagnosis and Treatment of COVID-19 Pneumonia published by the National Health Commission of the People's Republic of China (from February 5th, 2020 until now) [5-7]. Regarding treatment, the use of arbidol and traditional Chinese medicine may contribute to formulating a timely and effective therapeutic strategy to cure COVID-19 patients. To our knowledge, some traditional Chinese medicines have been shown to be effective in relieving the symptoms of COVID-19 patients $[8,9]$, especially Lianhuaqingwen capsules, as confirmed by a multicenter, prospective, randomized controlled trial directed by professor Nan-shan Zhong [9]. Moreover, the efficiency of arbidol has been shown in some clinical and basic studies [10-13], but there is a lack of validation by large sample size, multicenter, prospective, randomized controlled trials. Overall, traditional Chinese medicines and arbidol are referenced by Guidelines for the Diagnosis and Treatment of COVID-19 Pneumonia published by the National Health Commission of the People's Republic of China [4-7].

Author contributions JXL and GKF designed the study. QXG and GNW were major contributors in writing the manuscript. MYL revised the manuscript critically. All authors have read and approved the manuscript. Clinical and radiologic features of the first cured Coronavirus disease 2019 (COVID-19) patient in Guangzhou City, China.

\section{Compliance with ethical standards}

Conflict of interest The corresponding authors state that there is no conflict of interest.

Ethics approval Patient consent for publication of anonymized images was waived.

\section{References}

1. Bagiella E, Bhatt DL, Gaudino M. The consequences of the COVID-19 pandemic on non-COVID-19 clinical trials. J Am Coll Cardiol. 2020. https://doi.org/10.1016/j.jacc.2020.05.041.

2. Coronavirus disease (COVID-19) Situation Report-132, Data as received by WHO from national authorities by 10:00 CEST, 31 May 2020. https://www.who.int/docs/default-source/coronaviru se/situation-reports/20200531-covid-19-sitrep-132.pdf?sfvrs $\mathrm{n}=\mathrm{d} 9 \mathrm{c} 2$ eaef_2. Accessed 1 June 2020.

3. Ooi GC, Khong PL, Müller NL, Yiu WC, Zhou LJ, Ho JC, et al. Severe acute respiratory syndrome: temporal lung changes at thinsection CT in 30 patients. Radiology. 2004;230(3):836-44. https ://doi.org/10.1148/radiol.2303030853.

4. China National Health Commission, Diagnosis and treatment of pneumonitis caused by new coronavirus. (4th edition, in Chinese) https://www.nhc.gov.cn/yzygj/s7653p/202001/4294563ed35b432 09b31739bd0785e67.shtml. Accessed 27 Jan 2020.

5. China National Health Commission, Diagnosis and treatment of pneumonitis caused by new coronavirus. (5th edition, in Chinese) https://www.nhc.gov.cn/yzygj/s7653p/202002/3b09b894ac9b420 4a79db5b8912d4440.shtml. Accessed 5 Feb 2020.

6. China National Health Commission, Diagnosis and treatment of pneumonitis caused by new coronavirus. (6th edition, in Chinese). https://www.nhc.gov.cn/yzygj/s7653p/202002/8334a8326dd94d3 29df351d7da8aefc2.shtml. Accessed 19 Feb 2020.

7. China National Health Commission, Diagnosis and treatment of pneumonitis caused by new coronavirus. (7th edition, in Chinese) https://www.nhc.gov.cn/yzygj/s7653p/202003/46c9294a7dfe4ce f80dc7f5912eb1989.shtml. Accessed 3 Mar 2020.

8. Liu M, Gao Y, Yuan Y, Yang K, Shi S, Zhang J, et al. Efficacy and Safety of Integrated Traditional Chinese and Western Medicine for Corona Virus Disease 2019 (COVID-19): a systematic review and meta-analysis. Pharmacol Res. 2020. https://doi. org/10.1016/j.phrs.2020.104896.

9. Hu K, Guan WJ, Bi Y, Zhang W, Li L, Zhang B, et al. Efficacy and safety of lianhuaqingwen capsules, a repurposed Chinese herb, in patients with Coronavirus Disease 2019: a multicenter, prospective, randomized controlled trial. Phytomed Int J Phytother Phytopharmacol. 2020. https://doi.org/10.1016/j.phymed.2020.15324 2.

10. Xu P, Huang J, Fan Z, Huang W, Qi M, Lin X, et al. Arbidol/ IFN- $\alpha 2 b$ therapy for patients with corona virus disease 2019: a retrospective multicenter cohort study. Microbes Infect. 2020. https://doi.org/10.1016/j.micinf.2020.05.012.

11. Arbidol VN. A potential antiviral drug for the treatment of SARS$\mathrm{CoV}-2$ by blocking trimerization of the spike glycoprotein. Int J Antimicrob Agents. 2020. https://doi.org/10.1016/j.ijantimica g.2020.105998.

12. Deng L, Li C, Zeng Q, Liu X, Li X, Zhang H, et al. Arbidol combined with $\mathrm{LPV} / \mathrm{r}$ versus $\mathrm{LPV} / \mathrm{r}$ alone against corona virus 
disease 2019: a retrospective cohort study. J Infect. 2020. https:// doi.org/10.1016/j.jinf.2020.03.002.

13. Zhu Z, Lu Z, Xu T, Chen C, Yang G, Zha T, et al. Arbidol monotherapy is superior to lopinavir/ritonavir in treating COVID-19. J Infect. 2020. https://doi.org/10.1016/j.jinf.2020.03.060.
Publisher's Note Springer Nature remains neutral with regard to jurisdictional claims in published maps and institutional affiliations. 